\title{
Wave Control by Tide-Adapting Submerged Breakwater
}

\author{
Woo-Dong Lee $\circledast^{*}$, Yeon-Myeong Jeong $\overbrace{}^{* *}$ and Dong-Soo Hur@* \\ "Department of Ocean Civil Engineering, Gyeongsang National University, Tongyeong, Korea \\ Institute of Marine Industry, Gyeongsang National University, Tongyeong, Korea

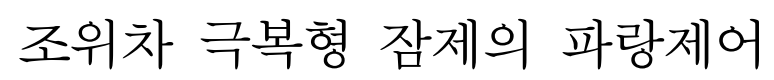

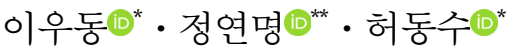 \\ *국립경상대학교 해양토목공학과 \\ "국립경상대학교 해양산업연구소
}

KEY WORDS: Tide-adapting submerged breakwater 조위차 극복형 잠제, Wave reflection 파랑 반사, Wave transmission 파랑 전달, Wave energy dissipation 파랑 에너지 감쇠, Breakwater development 방파제 개발, Hydraulic experiment 수리실험

\begin{abstract}
A submerged breakwater is a coastal structure built under water with excellent landscape. The depth of the crest of the breakwater should be maintained at more than a certain level in order for the submerged breakwater to control waves properly. This means that the effect of blocking waves deceases sharply at high tide in coastal areas with large tidal differences. In this study, we proposed a Tide-Adapting Submerged Breakwater (TA-SB) to overcome this problem, and then we conducted hydraulic model experiments to evaluate the performance of the TA-SB for controlling waves. The experimental results showed that the tapered wings attached to the crest of the TA-SB helped induce forced breaking waves. In particular, they were very effective in blocking waves and attenuating wave energy at high tide. In addition, the wave control performance of the proposed TA-SB was far superior to the Tide-Adapting Low-Crested Structure (TA-LCS) of the previous study.
\end{abstract}

\section{1. 서 론}

저마루 구조물(Low-crested structure, LCS) 중에서 잠제는 일 반 중력식 방파제와 달리 수면 아래에 위치하므로 경관이 좋고, 해수소통이 원활하다. 수중에 설치되는 잠제가 본연의 파랑제 어 기능을 제대로 발휘하기 위해서는 해역의 파랑조건을 고려 하여 일정 이상의 마루폭과 높이를 가져야 한다. 왜냐하면, 잠 제는 외해에서 끊임없이 유입되는 풍파를 마루 위에서 강제 쇄 파시킴으로써 파랑에너지가 소산되기 때문이다. 이에 많은 연 구자들이 잠제의 파랑제어 효과를 분석할 목적으로 수리모형실 험, 수치해석을 수행하였다(d'Angremond et al., 1996; Seabrook and Hall, 1998; Calabrese et al., 2002; van der Meer et al., 2005; Goda and Ahrens, 2008; Hur et al., 2012a; Hur et al., 2012b). 대 표적인 Hur et al.(2012b)의 수치해석결과에 따르면, 투과성 잠제 의 마루폭은 입사파장의 $1 / 4$ 이상, 마루수심은 입사파고의 $1 / 3$ 이하일 때, 배후 정온도 및 해안의 처오름 감소에 효과적인 것 으로 나타났다. 그렇다면 조위차가 큰 해역의 만조 시에는 잠제 가 파랑을 제어할 수 없게 된다. 조위차가 큰 해역에도 파랑 및
흐름제어 성능을 제대로 발휘할 수 있는 다기능 잠제 개발이 필요하다.

다기능 잠제의 연구사례를 살펴보면, Hur et al.(2010)은 수치 파동수조에서 투과성 잠제에 관로를 설치하여 배후수위를 하강 시킴으로써 개구부의 흐름을 감소시켰다. 이어서 Hur et al. (2017a)은 수리모형실험을 통해 잠제에 설치된 관로의 배후수위 저감효과를 재확인하였고, 3 차원 수치해석을 통해 잠제 개구부 의 흐름 저감을 위한 공법들이 검토되었다(Hur et al., 2014). 나 아가 Hur et al.(2019a)은 수리모형실험과 수치해석을 통해 배후 수위 상승 억제 목적의 관로가 설치된 잠제의 흐름제어 성능을 평가하였다. Hur et al.(2017b)은 부피가 큰 투과성 잠제의 단점 을 보완하고, 배후수위 조절, 흐름제어가 가능한 다열 벽체 잠 제를 수치파동수조에서 검토하였다. 최근에는 조위차를 극복하 기 위하여 Hur et al.(2019b)은 저마루 구조물의 상부(마루)에 날 개를 설치하고, 한쪽 끝에는 부유체를 부착하여 파랑운동에 따 라 날개가 움직이면서 파랑을 차단하는 TA-LCS(Tide-adapting low-crested structure)를 고안한 후, 수리모형실험을 통해 파랑차 단 효율을 일반 저마루 구조물과 비교·분석하였다. 또한 Hur

Received 3 September 2019, revised 23 November 2019, accepted 27 November 2019

Corresponding author Dong-Soo Hur: +82-55-772-9122, dshur@gnu.ac.kr ORCID: http://orcid.org/0000-0003-4627-7593

(c) 2019, The Korean Society of Ocean Engineers

This is an open access article distributed under the terms of the creative commons attribution non-commercial license (http://creativecommons.org/licenses/by-nc/3.0) which permits unrestricted non-commercial use, distribution, and reproduction in any medium, provided the original work is properly cited. 
et al.(2019c)는 Hur et al.(2019b)에서 논의되지 않았던 TA-LCS의 파랑의 전달계수, 반사계수, 감쇠계수 등에 관한 수리특성을 면 밀하게 조사하였다. 그러나 TA-LCS는 저마루 구조물임에도 날 개 일부가 부력으로 인해 수면 밖으로 돌출될 뿐 아니라, 고조 위에서 파랑 차단성능이 일반 잠제에 비해 다소 떨어지는 것으 로 나타났다.

본 연구에서는 Hur et al.(2019b)가 제안한 TA-LCS를 토대로 날개가 수면 밖으로 돌출되지 않는 형태의 TA-SB(Tide-adapting submerged breakwater)를 제안하고, 수리모형실험을 수행한다. 그 리고 조위변화에 따른 TA-SB의 수리성능을 일반 잠제와 비교 검토한다. 다음으로 Hur et al.(2019c)의 TA-LCS의 수리성능과 $\mathrm{TA}-\mathrm{SB}$ 를 비교하여 개선된 수리성능을 평가한다. 나아가 수리실 험결과에 기초하여 TA-SB의 파랑제어 메커니즘을 논의한다.

\section{2. 수리모형실험}

\section{1 실험수조의 개요}

본 연구에서 조위차 극복형 잠제의 파랑제어 기능을 길이
$30 \mathrm{~m}$, 폭 $0.4 \mathrm{~m}$, 높이 $0.9 \mathrm{~m}$ 의 2차원 실험수조(Fig. 1) 실험을 통해 분석한다. 실험수조에서 안정적인 파랑 생성을 위해서는 일정 이상의 수심 유지가 요구된다. 이를 위해 $1: 10$ 경사, $30 \mathrm{~cm}$ 높이 의 불투과성 기초바닥을 설치하여 조파기 위치에서 $57 \mathrm{~cm}$ 이상 의 수심을 확보하였다. 실험수조의 한쪽 끝에는 파랑반사를 최 소화 목적으로 $1: 7$ 경사의 투수층을 배치하였다. 기초바닥 위 에는 높이 $25 \mathrm{~cm}$, 마루폭 $30 \mathrm{~cm}$, 경사 $1: 1$ 의 불투과성 사다리꼴 잠제를 거치하였다. Fig. 1의 상세도와 같이 잠제 마루 위에는 두 께 $1.2 \mathrm{~cm}$ 의 날개를 설치하고, $10 \mathrm{~mm} \times 2 \mathrm{~mm}$ 철판으로 양쪽을 고정 하였다. 이 날개의 한쪽 끝의 마루수심 $\left(h_{c}\right)$ 은 $2 \mathrm{~cm}$ 로 일정하고, 수심 변화에 따라 날개 경사를 인위적으로 조절할 수 있다.

\section{2 실험조건과 측정방법}

본 수리모형실험에서는 Table 1과 같이 초기수심과 입사파랑 조건을 조합하여 총 27 가지를 고려한다. 실험조건은 크게 불투 과성 사다리꼴 잠제(Submerged breakwater, SB)와 마루 위에 날 개가 설치된 조위차 극복형 잠제(TA-SB)로 각각 구분된다. 그리 고 수심 $(h)$ 은 외해를 기준으로 일반 $\mathrm{SB}$ 는 $27 \mathrm{~cm}, \mathrm{TA}-\mathrm{SB}$ 는 조위

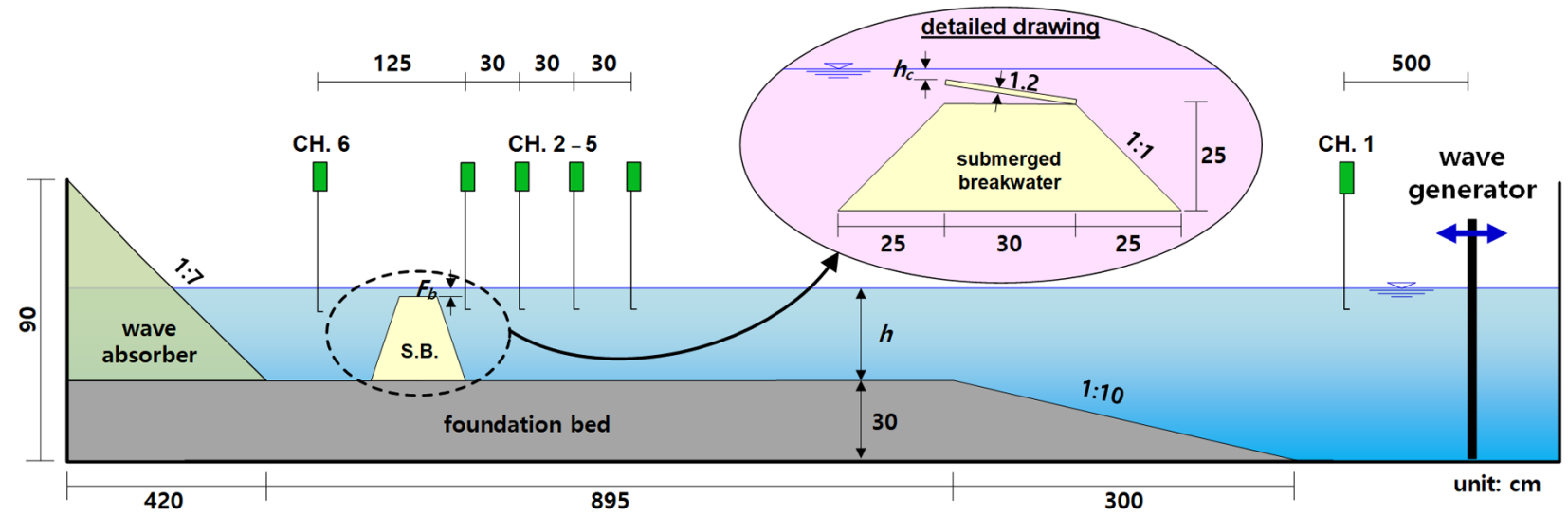

Fig. 1 Conceptual diagram of 2-D wave channel

Table 1 Experimental conditions

\begin{tabular}{|c|c|c|c|c|c|}
\hline \multirow[b]{2}{*}{ Run } & \multirow[b]{2}{*}{ Submerged breakwater model } & \multirow{2}{*}{$\begin{array}{l}\text { Depth } \\
h[\mathrm{~cm}]\end{array}$} & \multirow{2}{*}{$\begin{array}{c}\text { Crest depth } \\
h_{c}[\mathrm{~cm}]\end{array}$} & \multicolumn{2}{|c|}{ "Wave } \\
\hline & & & & $\begin{array}{c}\text { Height } \\
H_{i}[\mathrm{~cm}]\end{array}$ & $\begin{array}{c}\text { Period } \\
T_{i}[\mathrm{~s}]\end{array}$ \\
\hline $1-9$ & Typical SB & 27 & & & \\
\hline & & 32 & 2 & $3,5,7$ & $1.2,1.5,1.8$ \\
\hline $10-27$ & Tide-adapting SB & & & & \\
\hline & & 37 & & & \\
\hline
\end{tabular}


변화를 감안하여 $32 \mathrm{~cm}, 37 \mathrm{~cm}$ 를 각각 적용한다. 파랑조건은 규 칙파를 대상으로 입사파고 $\left(H_{i}\right) 3 \mathrm{~cm}, 5 \mathrm{~cm}, 7 \mathrm{~cm}$ 그리고 입사주기 ( $\left.T_{i}\right) 1.2 \mathrm{~s}, 1.5 \mathrm{~s}, 1.8 \mathrm{~s}$ 를 조합하여 9 가지를 구성한다.

시간파형 측정을 위해 6개 파고계를 실험수조에 배치하고, 조 파기로부터 이격거리 $5 \mathrm{~m}$ 에 Channel $(\mathrm{CH})$.1 , 잠제 전면에 $\mathrm{CH}$. $2-5$, 배후에 $\mathrm{CH} .6$ 을 각각 거치한다. 파고계로부터 $1 / 100$ 초 간격 으로 수위를 연속 저장한다.

\section{3 입 · 반사파 분리법}

잠제 전면에서 측정한 수면파형 $(\mathrm{CH} .2-5)$ 을 Goda and Suzuki (1976)의 입 - 반사파 분리법을 이용하여 반사계수 $\left(K_{R}\right)$, 잠제 배 후에서 측정한 수면파형 $(\mathrm{CH} .6)$ 으로 전달계수 $\left(K_{T}\right)$ 를 다음과 같 이 각각 산정한다.

Fig. 2처럼 입사파와 반사파가 공존하는 중복파동장에서 같은 파수에 다른 진폭과 위상각을 가진 입사파형 $\left(\eta_{I}\right)$ 과 반사파형 $\left(\eta_{R}\right)$ 으로 식 (1)-(2)와 같다.

$$
\begin{aligned}
& \eta_{I}=\alpha_{I} \cos \left(k x-\sigma t+\epsilon_{I}\right) \\
& \eta_{R}=\alpha_{R} \cos \left(k x-\sigma t+\epsilon_{R}\right)
\end{aligned}
$$

여기서 $\alpha$ 는 진폭, $k(=2 \pi / L)$ 는 파수, $\sigma(=2 \pi / T)$ 는 각주파수, $\epsilon$ 는 위상각, $L$ 은 파장, $T$ 는 주기이며, 아래 첨자 $I, R$ 은 입사파와 반사파를 나타낸다.

Fig. 2로부터 $\Delta l$ 만큼 떨어진 2지점 $x=x_{1}$ 와 $x=x_{2}=x_{1}+\Delta l$ 에 서 동시에 측정된 파형은 일반적으로 식 (3)-(4)와 같이 나타낸다.

$$
\begin{aligned}
& \eta_{I}=\left(\eta_{I}+\eta_{R}\right)_{x=x_{1}}=A_{1} \cos \sigma t+B_{1} \sin \sigma t \\
& \eta_{R}=\left(\eta_{I}+\eta_{R}\right)_{x=x_{2}}=A_{2} \cos \sigma t+B_{2} \sin \sigma t
\end{aligned}
$$

위 식에서 $A_{1}, B_{1}, A_{2}, B_{2}$ 는 다음과 같다.

$$
\begin{aligned}
& A_{1}=\alpha_{I} \cos \phi_{I}+\alpha_{R} \cos \phi_{R} \\
& B_{1}=\alpha_{I} \sin \phi_{I}+\alpha_{R} \sin \phi_{R} \\
& A_{2}=\alpha_{I} \cos \left(k \Delta l+\phi_{I}\right)+\alpha_{R} \cos \left(k \Delta l+\phi_{R}\right) \\
& B_{2}=\alpha_{I} \sin \left(k \Delta l+\phi_{I}\right)+\alpha_{R} \sin \left(k \Delta l+\phi_{R}\right)
\end{aligned}
$$

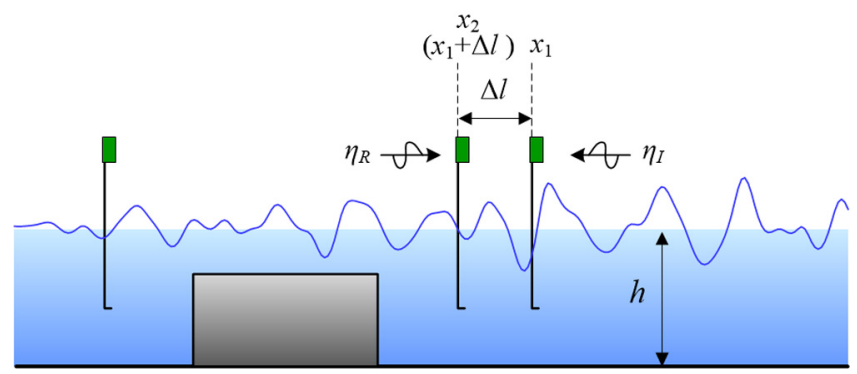

Fig. 2 Definition sketch of wave field around a structure
여기서

$$
\begin{aligned}
& \phi_{I}=k x_{1}+\epsilon_{I} \\
& \phi_{R}=k x_{2}+\epsilon_{R}
\end{aligned}
$$

위 식 (5)-(8)은 4개 미지수 $\left(\alpha_{I}, \alpha_{R}, \phi_{I}, \phi_{R}\right)$ 에 대한 방정식이고, 식 (7)-(8)에서 $\alpha_{R}, \phi_{R}$ 을 제거하면, 다음의 식 (11)-(12)와 같다.

$$
\begin{aligned}
& A_{2}=\left(A_{1} \cos k \Delta l+B_{1} \sin k \Delta l\right)-2 \alpha_{I} \sin k \Delta l \sin \phi_{I} \\
& B_{2}=\left(-A_{1} \sin k \Delta l+B_{1} \cos k \Delta l\right)+2 \alpha_{I} \sin k \Delta l \sin \phi_{I}
\end{aligned}
$$

위 식 (11)-(12)에서 $\phi_{I}$ 를 제거하기 위해서는 $\alpha_{I}$ 가 필요하며, 같은 연산을 수행하기 위해서는 $\alpha_{R}$ 도 필요하다. 여기서 $\alpha_{I}$ 와 $\alpha_{R}$ 는 다음 식 (13)-(14)와 같이 산정될 수 있다.

$$
\begin{aligned}
& \alpha_{I}=\frac{1}{2|\sin k \Delta l|} \\
& {\left[\left(A_{2}-A_{1} \cos k \Delta l-B_{1} \sin k \Delta l\right)^{2}+\left(B_{2}+A_{1} \sin k \Delta l-B_{1} \cos k \Delta l\right)^{2}\right]^{1 / 2}} \\
& \alpha_{R}=\frac{1}{2|\sin k \Delta l|} \\
& {\left[\left(A_{2}-A_{1} \cos k \Delta l+B_{1} \sin k \Delta l\right)^{2}+\left(B_{2}-A_{1} \sin k \Delta l+B_{1} \cos k \Delta l\right)^{2}\right]^{1 / 2}}
\end{aligned}
$$

여기서 입 - 반사파의 주파수 $\left(f_{m}\right)$ 의 성분파 진폭을 $\alpha_{I}(m), \alpha_{R}(m)$ 으로 나타내면, 입-반사파의 추정 스펙트럼 밀도 $S_{I}\left(f_{m}\right)$ 과 $S_{R}\left(f_{m}\right)$ 은 다음 식 (15)-(16)으로 정의된다.

$$
\begin{aligned}
& S_{I}\left(f_{m}\right)=\frac{1}{2} \alpha_{I}^{2}(m) N \Delta t \\
& S_{R}\left(f_{m}\right)=\frac{1}{2} \alpha_{R}^{2}(m) N \Delta t
\end{aligned}
$$

여기서 $N$ 은 시계열 데이터를 불연속화 했을 때의 데이터 수, $\Delta t$ 는 샘플링 타임이다. 또한 입사파와 반사파의 에너지 $E_{I}, E_{R}$ 은 위 식에서 추정한 스펙트럼 밀도를 Goda and Suzuki(1976)에 의해 정의된 유효 주파수 범위에서 적분 값으로 표현된다. 이상 의 결과로부터 반사계수 $\left(K_{R}\right)$ 은 다음 식(17)과 같다.

$$
K_{R}=\sqrt{E_{R} / E_{I}}
$$

전달계수 $\left(K_{T}\right)$ 는 구조물 배후에 설치된 파고계에서 얻은 파형 데이터를 FFT(First fourier transformation)에 의해 각 주파수 성 분파로 분리하고, 각 주파수 성분파 에너지의 합으로 산정한 투 과파의 에너지 $E_{T}$ 와 입사파 에너지 $E_{I}$ 를 사용하여 다음 식(18) 과 같이 얻을 수 있다.

$$
K_{R}=\sqrt{E_{T} / E_{I}}
$$

파랑에너지 감쇠의 정도를 나타내는 감쇠계수 $\left(K_{D}\right)$ 는 $K_{R}$ 과 $K_{T}$ 를 고려하여 다음 식 (19)와 같이 구한다. 


$$
K_{D}=\sqrt{1-K_{R}^{2}-K_{T}^{2}}
$$

\section{3. 수리성능 분석}

\section{1 파동장}

Fig. 3-5는 파형경사가 가장 작은 입사파랑 $\left(H_{i}=3 \mathrm{~cm}, T_{i}=\right.$ $1.8 \mathrm{~s})$ 유입 시, 촬영한 영상으로부터 잠제 주변의 파동장을 $t / T_{i}=1 / 10$ 간격으로 추출한 것이다. 여기서 Fig. 3, Fig. 4, Fig. 5 의 수위는 각각 $27 \mathrm{~cm}, 32 \mathrm{~cm}, 37 \mathrm{~cm}$ 이며, 마루수심 $2 \mathrm{~cm}$ 를 유지 하기 위해 Fig. 4와 Fig. 5는 날개가 경사 배치되었다.
Fig. 3의 일반 $\mathrm{SB}$ 에서는 파봉이 유입되는 (c) $t / T_{i}=1 / 10$ 에서 쇄파가 발생하지 않는다. 그러나 Fig. 4와 Fig. 5처럼 TA-SB의 마루 위에서는 쇄파가 발생한다. 이것은 경사 날개에 기인한 천 수효과에 의해 유입 파랑의 비선형성과 파형경사가 증가하여 쇄파가 용이해지기 때문이다. 이 현상은 수심이 깊고, 날개 경 사가 급한 Fig. 5에서 더욱 강하게 나타난다.

Fig. 6-8은 전술한 Fig. 3-5의 경우보다 쇄파에 유리한 파형경 사가 가장 큰 입사파랑 $\left(H_{i}=7 \mathrm{~cm}, T_{i}=1.2 \mathrm{~s}\right)$ 유입 시, 촬영한 영 상으로 잠제 주변의 파동장을 $t / T_{i}=1 / 10$ 간격으로 추출한 것 이다. 여기서 Fig. 6-8의 수위는 $27 \mathrm{~cm}, 32 \mathrm{~cm}, 37 \mathrm{~cm}$ 이고, 마루수 심은 $2 \mathrm{~cm}$ 로 유지된다. 그리고 Fig. 6 은 일반 $\mathrm{SB}$, Fig. 7과 Fig. 8

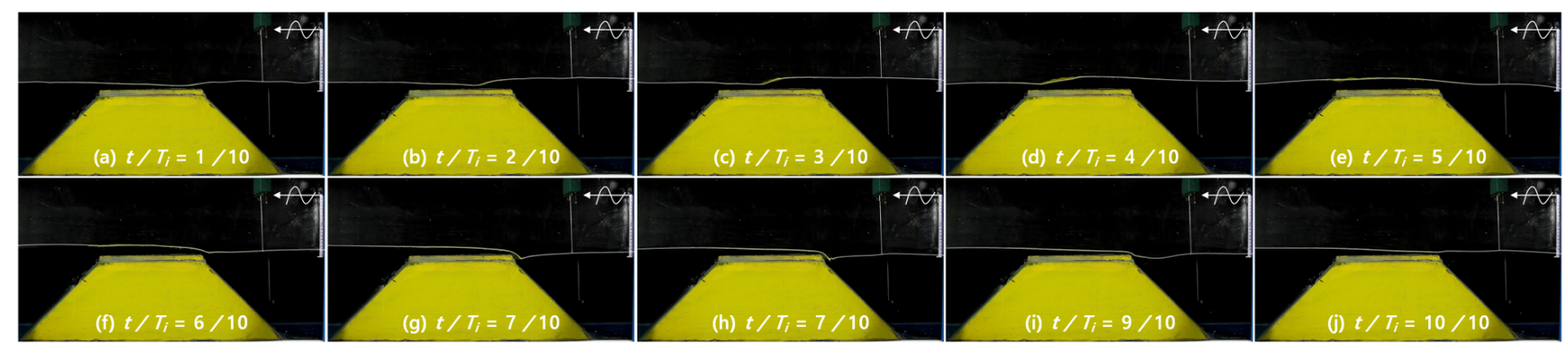

Fig. 3 Temporal and spatial distributions of surface elevations around typical submerged breakwater in Run-3 $(h=27 \mathrm{~cm})$
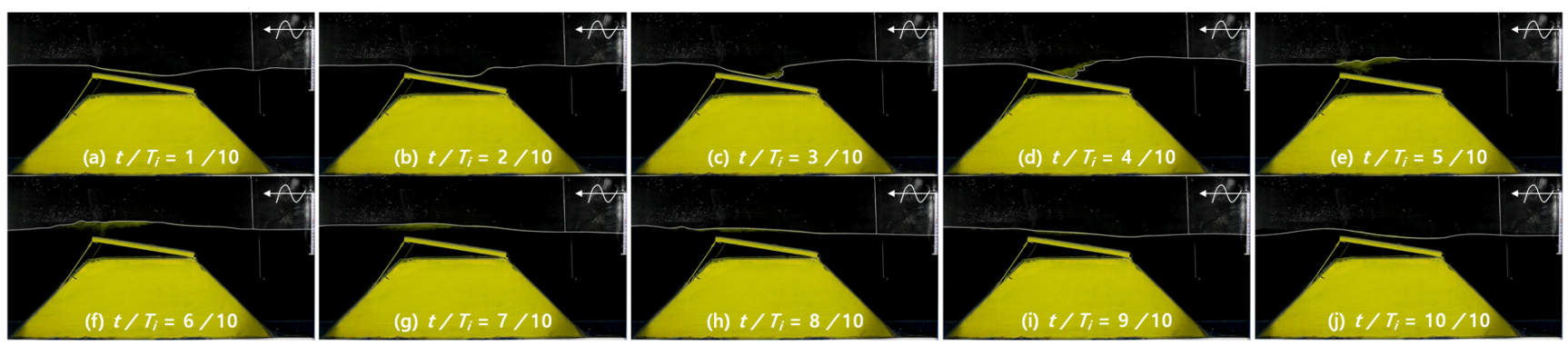

Fig. 4 Temporal and spatial distributions of surface elevations around tide-adapting submerged breakwater in Run-12 $(h=32 \mathrm{~cm})$

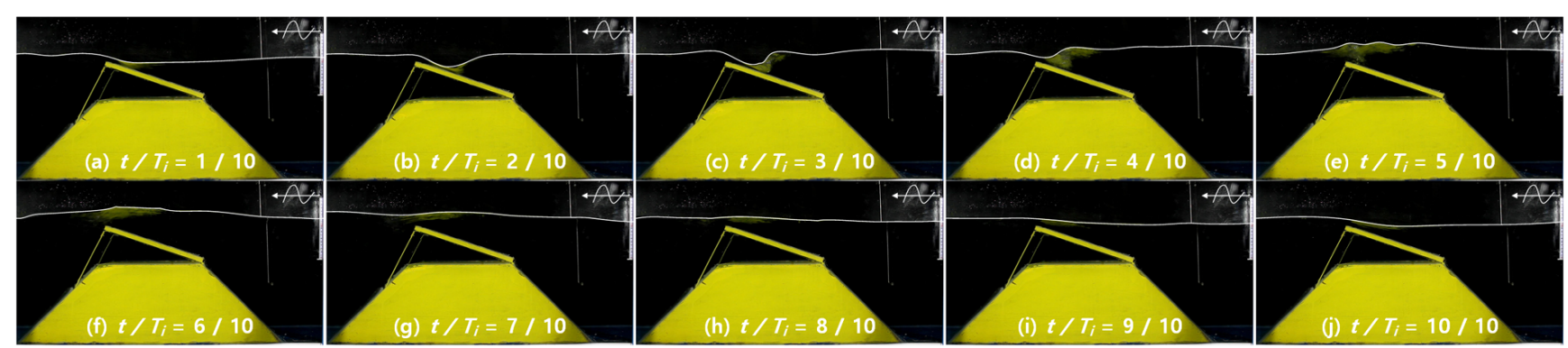

Fig. 5 Temporal and spatial distributions of the surface elevations around tide-adapting submerged breakwater in Run-21 ( $h=37 \mathrm{~cm})$

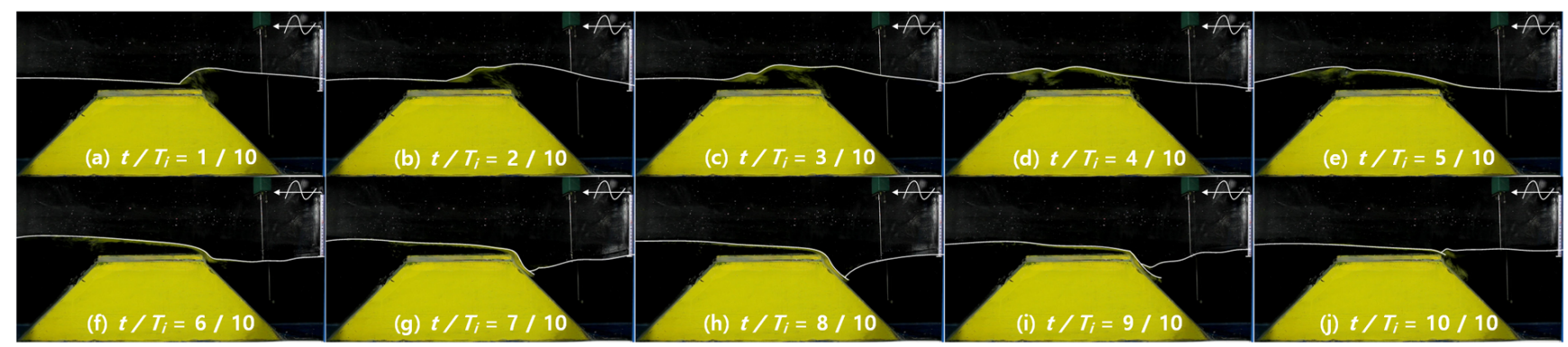

Fig. 6 Temporal and spatial distributions of surface elevations around typical submerged breakwater in Run-7 $(h=27 \mathrm{~cm})$ 


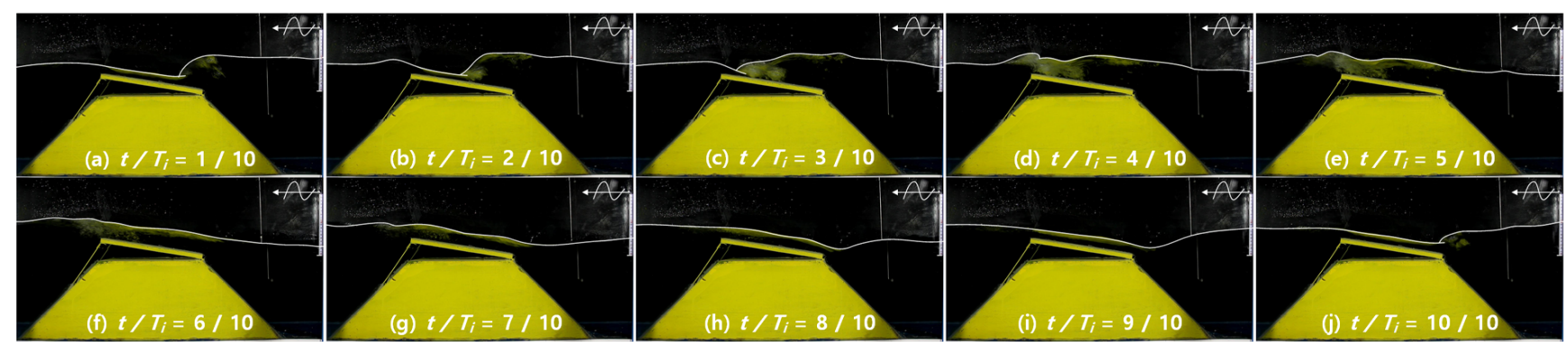

Fig. 7 Temporal and spatial distributions of surface elevations around tide-adapting submerged breakwater in Run-16 $(h=32 \mathrm{~cm})$

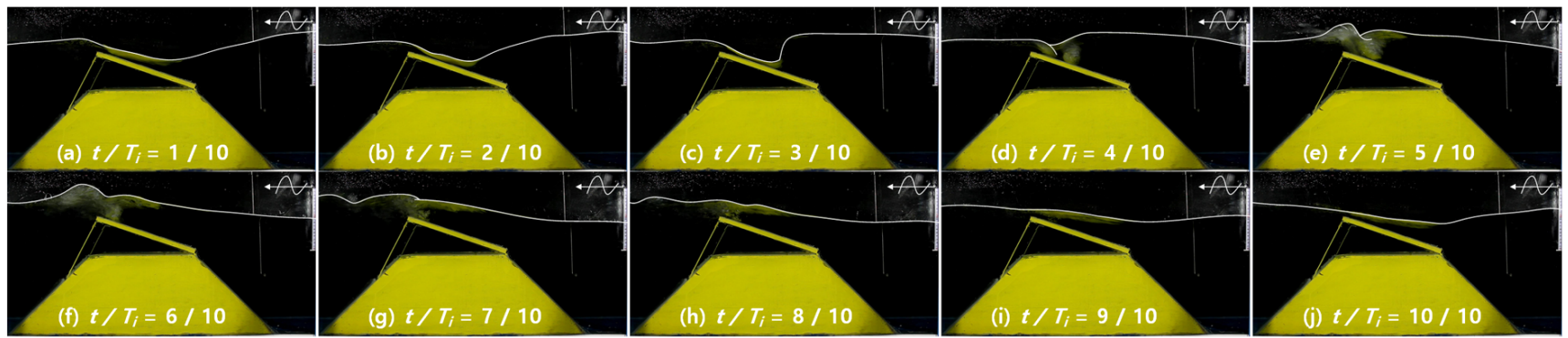

Fig. 8 Temporal and spatial distributions of surface elevations around tide-adapting submerged breakwater in Run- $25(h=37 \mathrm{~cm})$

은 마루 위에 날개가 부착된 TA-SB이다.

Fig. 6-8로부터 파형경사가 가장 큰 파랑에서는 모든 잠제 모 형에서 쇄파가 발생한다. 그러나 일반 $\mathrm{SB}$ 보다는 마루 위에 경 사 날개가 부착된 TA-SB에서 쇄파가 더 강하게 나타난다. 이것 은 앞서 논의한 바와 같이 마루 위의 경사 날개에 의한 천수효 과가 유입 파랑의 비선형성과 파형경사를 크게 증가시켜 강한 쇄파를 유도하기 때문이다. 그리고 수심이 깊고, 날개 경사가 급한 $\mathrm{TA}-\mathrm{SB}$ 에서 두드러진 강제 쇄파가 관찰된다.

이상에 근거하여 $\mathrm{TA}-\mathrm{SB}$ 는 일반 $\mathrm{SB}$ 에서 쇄파가 발생하지 않 는 파랑조건에서도 강제쇄파가 유도되고, 쇄파가 발생하는 파 랑조건에서는 더욱 강한 쇄파가 나타난다. 이로써 TA-SB는 조 위 상승 시에 잠제가 가진 본연의 파랑제어 기능이 향상됨을 확인할 수 있다. 이어서 파랑의 전달계수 $\left(K_{T}\right)$, 반사계수 $\left(K_{R}\right)$, 감쇠계수 $\left(K_{D}\right)$ 를 비교 - 검토하여 TA-SB의 수리성능을 정량적으 로 조사한다.

\section{2 전달계수}

Fig. 9에서는 TA-SB의 파랑차단 효과를 비교 - 분석하기 위하 여 쇄파상사계수 $\left(\zeta=\tan \alpha / \sqrt{H_{i} / L_{i}} ; \alpha\right.$ 는 구조물의 외측 경사, $H_{i} / L_{i}$ 는 파형경사)에 따른 파랑 전달계수 $\left(K_{T}\right)$ 를 나타낸다. 그래 프에서 검정색 원은 $h=27 \mathrm{~cm}$ 의 일반 $\mathrm{SB}$, 파란색 역삼각형은 $h=32 \mathrm{~cm}$ 의 $\mathrm{TA}-\mathrm{SB}$, 빨강색 삼각형은 $h=37 \mathrm{~cm}$ 의 $\mathrm{TA}-\mathrm{SB}$ 의 경우 를 각각 나타낸다. 그리고 실선은 각각의 경향선이다.

Fig. 9에서는 $\zeta$ 가 작을수록 잠제 마루 상에서 쇄파가 용이함 으로 $K_{T}$ 가 작아지는 경향이 뚜렷하게 나타난다. 그리고 일반적 으로 조위가 상승할수록 잠제의 파랑 전달계수는 증가하기 마 련이다. 그러나 $\mathrm{TA}-\mathrm{SB}$ 는 고조위에서 도리어 $K_{T}$ 가 작아진다. 이 것은 앞서 논의한 파동장 분석처럼 $\mathrm{TA}-\mathrm{SB}$ 가 일반 $\mathrm{SB}$ 보다 쇄파 유도에 유리할 뿐 아니라, TA-SB에 부착되는 경사 날개로 인해 강한 쇄파가 발생하기 때문이다.

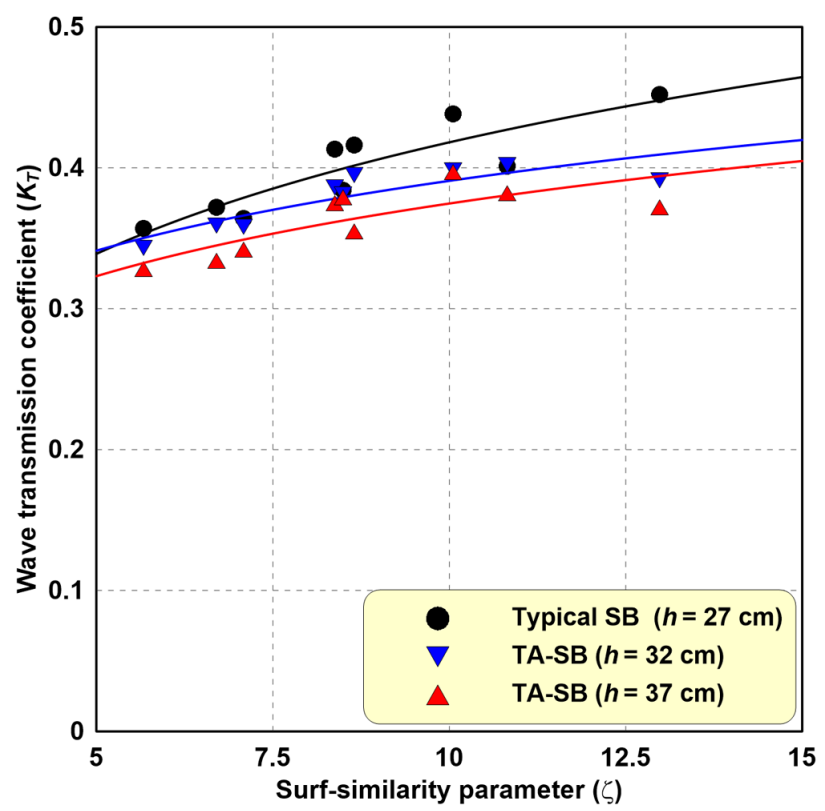

Fig. 9 Distributions of wave transmission coefficients

\section{3 반사계수}

Fig. 10은 Goda and Suzuki(1976)의 입 - 반사파 분리법을 이용 하여 산정한 반사계수 $\left(K_{R}\right)$ 를 쇄파상사계수 $(\zeta)$ 에 따라 나타낸 것 이다. 여기서 그래프에 표시된 기호들은 Fig. 9의 설명과 같다.

Fig. 10으로부터 가 증가할수록 쇄파가 약하게 발생함으로 $K_{R}$ 이 커지는 경향을 보인다. 이것은 쇄파가 강할수록 $K_{R}$ 이 작 아진다는 뜻이기도 하다. Fig. 10에서 강한 쇄파가 발생하는 $\mathrm{TA}-\mathrm{SB}$ 의 $K_{R}$ 이 일반 $\mathrm{SB}$ 보다 작은 것으로 보아 이것 역시 잠제 의 마루 상에서 발생하는 쇄파와 밀접한 관계가 있음을 알 수 있다. 그리고 TA-SB는 고조위 조건에서 더 강한 쇄파가 발생함 으로 상대적으로 작은 $K_{R}$ 분포를 나타낸다. 


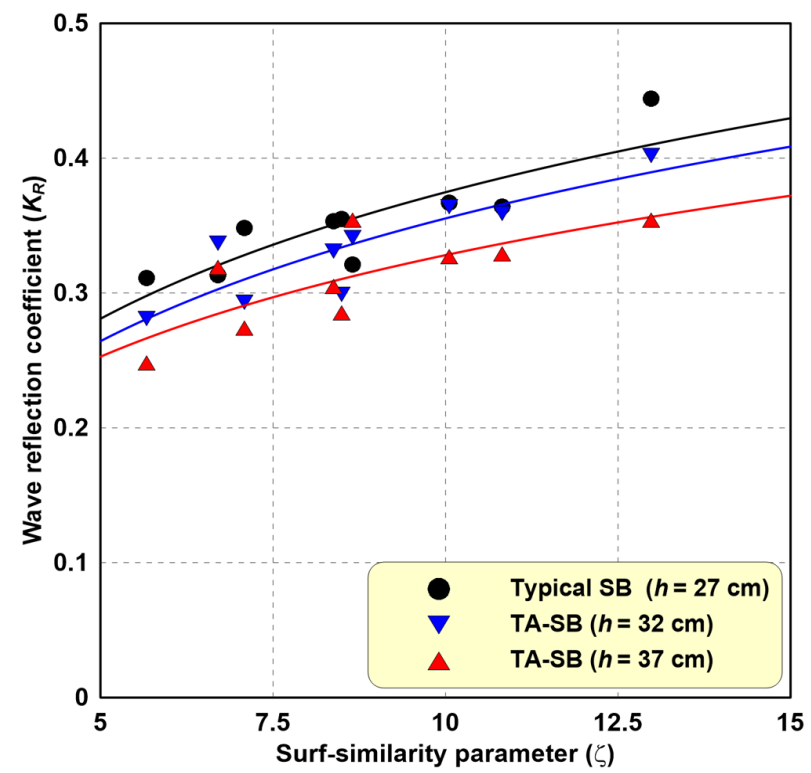

Fig. 10 Distributions of wave reflection coefficients

\section{4 감쇠계수}

Fig. 11은 식 (19)와 같이 앞서 논의한 $K_{T}$ 와 $K_{R}$ 을 고려하여 산정한 파랑에너지 감쇠계수 $\left(K_{D}\right)$ 를 쇄파상사계수 $(\zeta)$ 에 따라 나

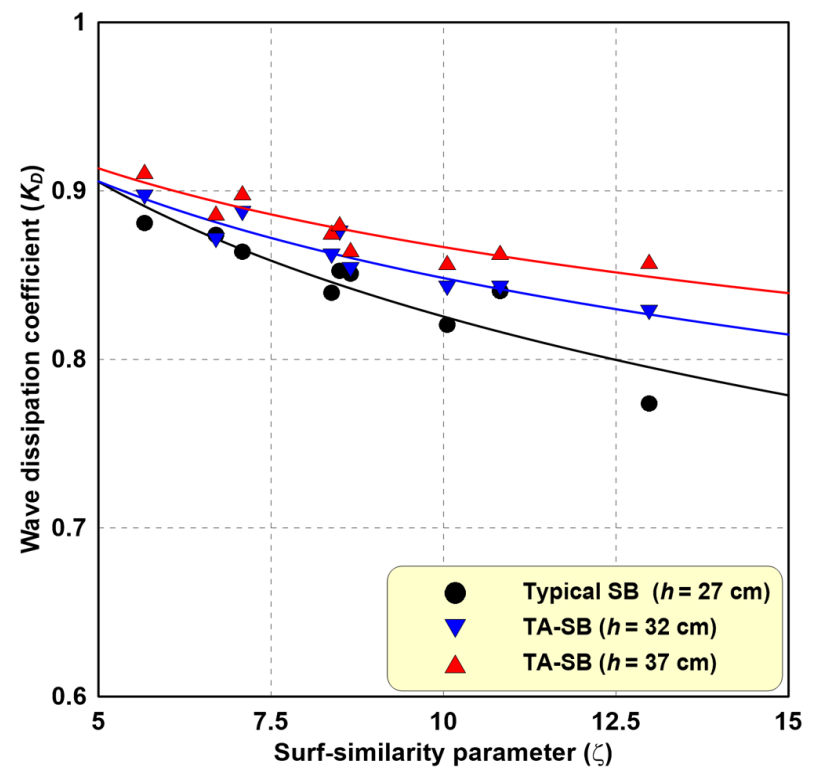

Fig. 11 Distributions of wave dissipation coefficients
타낸 것이다. 여기서 그래프에 표시된 기호들은 Fig. 9의 설명과 같다.

Fig. 11로부터 TA-SB의 $K_{D}$ 는 일반 SB보다 크며, Fig. 3-8을 상호 비교하여 그 원인을 다음처럼 분석할 수 있다. 일반 $\mathrm{SB}$ (Fig. 3)의 비쇄파 파랑조건에서도 TA-SB(Fig. 4-5)는 날개 위에 서 강제 쇄파가 일어난다. 그리고 모든 잠제 모형에서 쇄파가 발생하는 경우에도 TA-SB(Fig. 7-8)가 일반 $\mathrm{SB}$ (Fig. 6)보다 더 강한 쇄파가 나타난다. 이것은 TA-SB의 경사 날개가 유입 파랑 의 비선형성이 증가시켜 강제 쇄파를 유도하기 때문이며, 이 현 상은 날개 경사가 급할수록 두드러진다. 그 결과, 강한 쇄파가 발생하는 $\mathrm{TA}-\mathrm{SB}$ 의 $K_{T}$ 와 $K_{R}$ 이 작아짐으로 $K_{D}$ 또한 일반 $\mathrm{SB}$ 보 다 크다.

\section{4. 수리성능 비교}

TA-SB의 수리성능을 선행연구인 Hur et al.(2019b)와 Hur et al.(2019c)에서 제안한 조위차 극복형 저마루 구조물(TA-LCS) 와 비교 - 분석한다. Fig. 12처럼 TA-LCS는 잠제 마루에 설치 된 날개의 끝에 부력제가 부착되어 있어서 수위변동(파랑작용) 에 따라 날개의 일정 부분이 수면 밖으로 항시 돌출되는 형태 이다. 그리고 TA-LCS의 제원 및 실험조건은 본 연구의 TA-SB 와 같다.

\section{1 전달계수}

Fig. 13 에서는 TA-SB의 파랑차단 성능을 평가하기 위해 TA-LCS의 파랑 전달계수 $\left(K_{T}\right)$ 와 비교하여 나타낸다. 그래프에서 파란색 역삼각형은 $h=32 \mathrm{~cm}$, 빨강색 삼각형은 $h=37 \mathrm{~cm}$ 조건이 고, 속이 꽉 찬 도형은 TA-SB, 속이 빈 도형은 TA-LCS의 경우를 각각 의미한다. 그리고 실선과 점선은 각각의 경향선이다.

Fig. 13으로부터 TA-SB의 $K_{T}$ 가 TA-LCS의 경우보다 전체적 으로 작다. TA-LCS의 경우는 고조위에서 $K_{T}$ 가 큰데 반면, $\mathrm{TA}-\mathrm{SB}$ 의 경우는 고조위에서 $K_{T}$ 가 더 작다. 그리고 $\zeta$ 가 클수록 $K_{T}$ 가 증가하며, TA-LCS의 경향선 기울기는 더 크다.

다시 말해 TA-SB의 파랑차단 성능이 TA-LCS에 비해 다음 3 가지 면에서 우수하다고 판단된다. 첫째, $\mathrm{TA}-\mathrm{SB}$ 의 고정된 경사 날개가 강제 쇄파를 유도함으로써 $K_{T}$ 가 작다. 둘째, 수심이 깊 은 조건에서 $K_{T}$ 가 더 작기 때문에 $\mathrm{TA}-\mathrm{SB}$ 는 고조위를 충분히 극복할 수 있다. 셋째, TA-SB의 경향선 기울기가 완만함으로 배 후 정온도 확보에 유리하다.

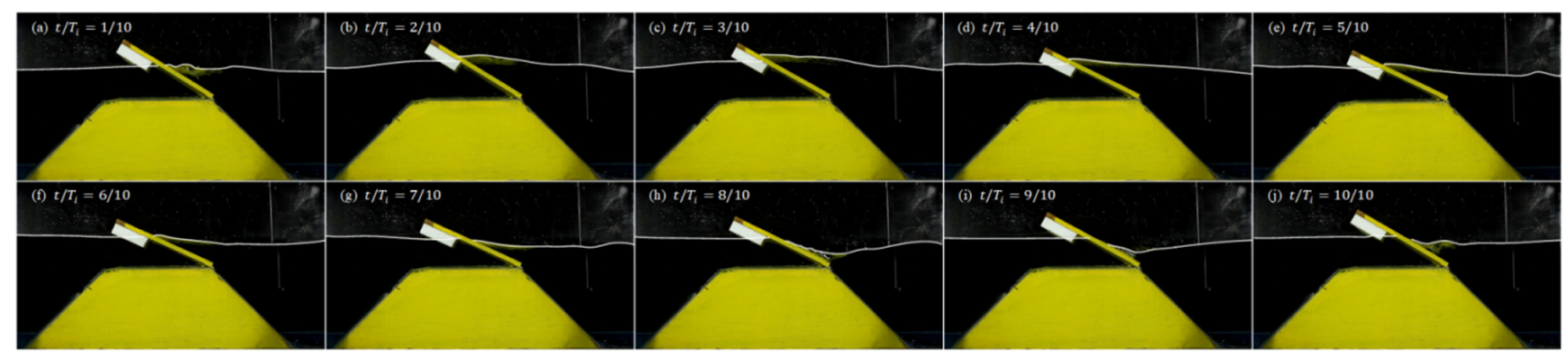

Fig. 12 Overview of tide-adapting low-crested structure (Hur et al., 2019c) 


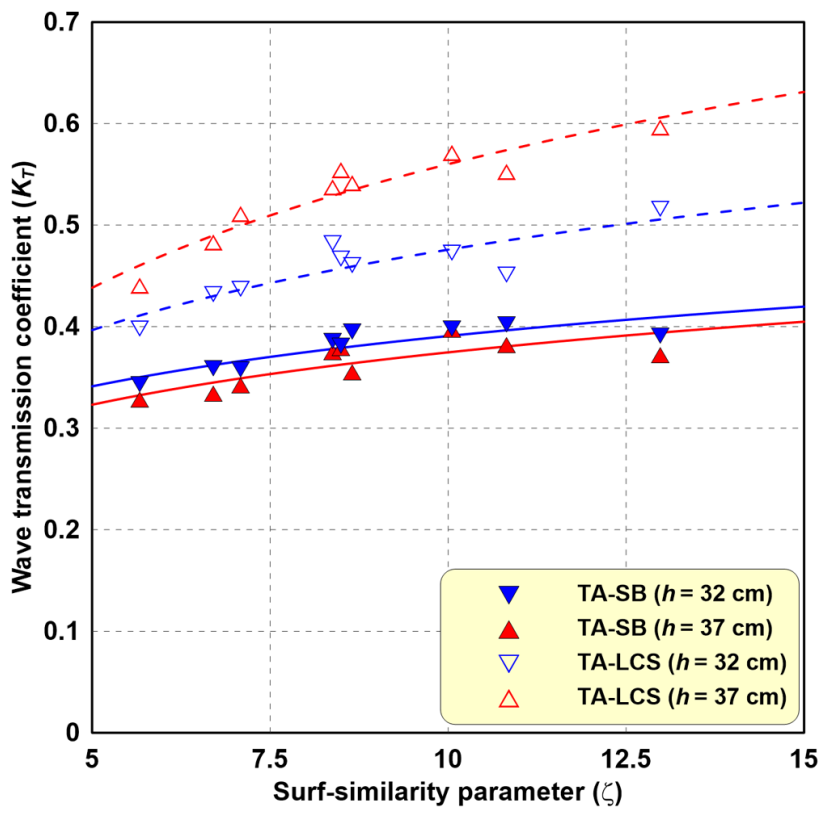

Fig. 13 Comparisons of wave transmission coefficients

\section{2 반사계수}

Fig. 14는 Goda and Suzuki(1976)의 입 - 반사파 분리법을 이용 하여 산정한 TA-SB와 TA-LCS의 반사계수 $\left(K_{R}\right)$ 를 $\zeta$ 에 따라 비 교한 것이다. 여기서 그래프에 표시된 기호들은 Fig. 13의 설명 과 동일하다.

Fig. 14에서 $\zeta$ 가 증가할수록 $K_{R}$ 이 커지는 경향을 보이고, TA-SB가 TA-LCS보다 $K_{R}$ 이 전반적으로 크다. 이것은 TA-SB는 날개가 고정되어 있고, TA-LCS는 수위변화에 따라 날개가 움직 이기 때문에 나타나는 차이로 이해된다. 조위차가 큰 해역에서 반사파랑 제어성능만 놓고 비교한다면, TA-LCS가 TA-SB보다 우수하다.

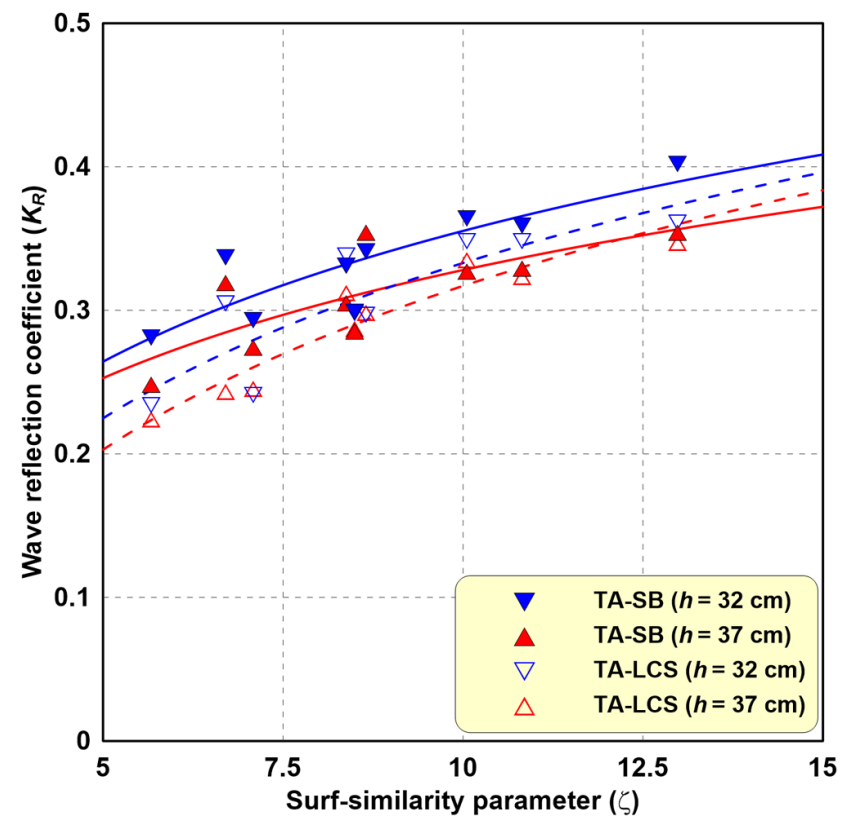

Fig. 14 Comparisons of wave reflection coefficients

\section{3 감쇠계수}

Fig. 15는 $K_{T}$ 와 $K_{R}$ 을 식 (19)에 대입하여 얻은 파랑에너지 감쇠계수 $\left(K_{D}\right)$ 이며, $\zeta$ 에 따라 나타낸다. 여기서 그래프에 표시된 기호들은 Fig. 13 의 경우와 같다.

Fig. 15 로부터 TA-SB의 $K_{D}$ 가 TA-LCS의 경우보다 전체적으 로 크다. TA-LCS는 고조위 조건에서 $K_{D}$ 가 더 작고, TA-SB는 고조위 조건에서 $K_{D}$ 가 더 크다. 그리고 $\zeta$ 와 $K_{D}$ 는 반비례이며, $\mathrm{TA}-\mathrm{SB}$ 의 경향선 기울기가 더 완만하다. 이것은 $\mathrm{TA}-\mathrm{SB}$ 의 경우 에는 모든 실험조건에서 쇄파로 파랑에너지 소산이 일어나기 때문에 전체적으로 $K_{D}$ 가 크다. 특히 고조위에서 강한 쇄파를 유도함으로써 $K_{D}$ 는 더 크다. 이에 반해 날개가 수면 밖으로 돌 출되어 쇄파 없이 파랑을 차단하는 TA-LCS는 상대적으로 에너 지의 소산이 작다.

수리성능 비교결과에 근거하여 $\mathrm{TA}-\mathrm{SB}$ 는 마루 위에 고정된 경사 날개의 강제 쇄파 유도에 따른 파랑에너지 감쇠가 파랑 전달을 감소시켰다. 그 까닭에 $\mathrm{TA}-\mathrm{SB}$ 는 마루에 부착된 날개가 자유롭게 움직이는 TA-LCS에 비해 파랑제어 효과가 우수할 뿐 만 아니라, 고조위에서 더욱 강한 쇄파를 발생시켜 수리성능을 크게 향상시켰다.

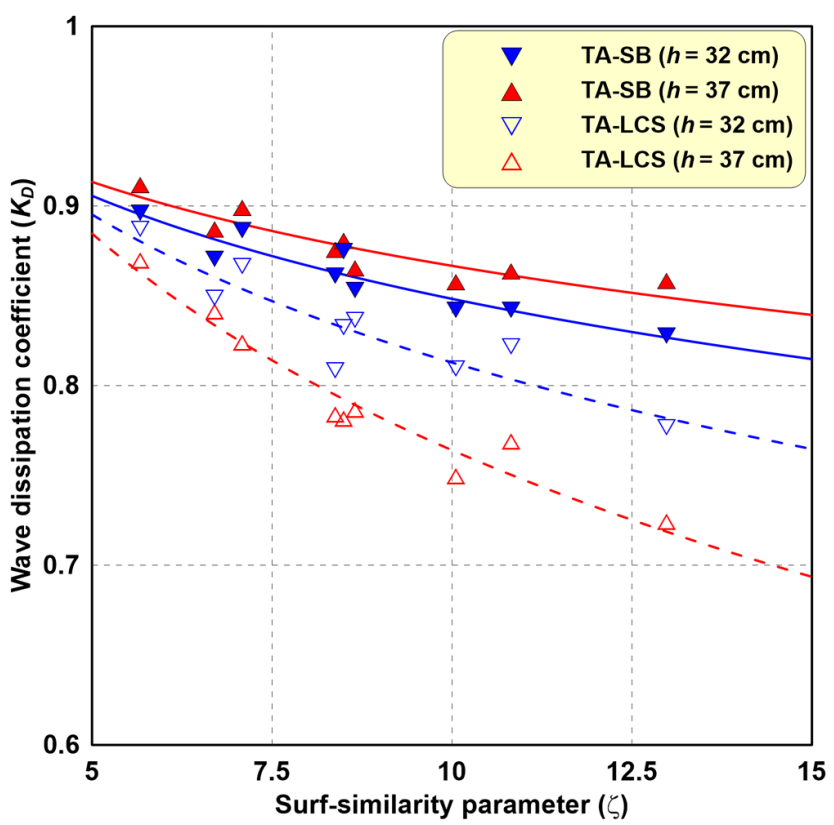

Fig. 15 Comparisons of wave dissipation coefficients

\section{5. 결 론}

조위차가 큰 해역에서도 파랑제어 기능을 제대로 수행할 수 있는 조위차 극복형 잠제(TA-SB)를 본 연구에서 제안하였다. 그 리고 수리모형실험의 영상자료로부터 잠제 마루 위에서의 강제 쇄파 메커니즘을 논의할 수 있었다. 나아가 실험수조에서 측정 한 시간파형을 입 - 반사파 분리하여 파랑의 전달계수, 반사계 수, 감쇠계수를 각각 산정한 후, TA-SB의 수리성능을 일반 $\mathrm{SB}$, TA-LCS와 비교 - 분석하였다. 본 연구에서 얻어진 주요한 결과 들은 다음과 같다. 
(1) TA-SB 및 일반 SB 주변의 파동장을 비교하여 TA-SB의 강제 쇄파 유도과정을 분석하였다. TA-SB의 경사 날개로 인해 파랑의 비선형성 및 파형경사가 증가하여 쇄파가 용이해졌다.

(2) 모든 잠제 모형에서 $\zeta$ 가 증가할수록 $K_{T}$ 와 $K_{R}$ 은 증가, $K_{D}$ 는 감소하였고, $\mathrm{TA}-\mathrm{SB}$ 의 파랑제어 성능은 일반 $\mathrm{SB}$ 보다 우수하 였다.

(3) TA-SB의 파랑제어 효과는 고조위에서 두드러지게 나타났 다. 이것은 고조위 조건에서 $\mathrm{TA}-\mathrm{SB}$ 의 경사 날개 위에서 강한 쇄파가 발생하기 때문이다.

(4) TA-SB를 기존 TA-LCS와 비교하면, $K_{T}$ 는 작고, $K_{R}$ 는 조 금 크고, $K_{D}$ 는 크다. 이것은 날개가 파랑을 전달을 차단하는 TA-LCS보다 경사 날개가 강제 쇄파를 유도하는 TA-SB의 파랑 제어 성능이 탁월하기 때문이다.

이상의 실험결과에 근거하여 고조위에서 TA-SB의 수리성능 이 일반 SB와 TA-LCS보다 우수하기 때문에 조위차를 충분히 극복할 수 있을 것으로 판단된다. 하지만 $\mathrm{TA}-\mathrm{SB}$ 를 조위차가 큰 해역에 설치하기 위해서는 수위변화에 따라 TA-SB의 경사 날 개의 기울기를 자동 조절할 수 있는 별도 장치가 필요하다. 또 한 $\mathrm{TA}-\mathrm{SB}$ 의 경사 날개의 구조적 안정성도 충분히 검토되어야 한다.

$$
\text { 후 기 }
$$

이 논문은 2018년 해양수산부 재원으로 해양수산과학기술진 흥원의 지원을 받아 수행된 연구임(연안침식 관리 및 대응기술 실용화).

\section{References}

Calabrese, M., Vicinanza, V., Buccino, M., 2002. Large Scale Experiments on the Behaviour of Low Crested and Submerged Breakwaters in Presence of Broken Waves. Proceedings of the 28th International Conference on Coastal Engineering, ASCE, 1900-1912. https://doi.org/10.1142/9789812791306_0160

Goda, Y., Ahrens, J.P., 2008. New Formulation of Wave Transmission over and through Low-Crested Structures. Proceedings of the 31st International Conference on Coastal Engineering, ASCE, 3530-3541. https://doi.org/10.1142/978 9814277426_0293

Goda, Y., Suzuki, Y., 1976. Estimation of Incident and Reflected Waves in Random Wave Experiments. Proceedings of 15th International Conference Coastal Engineering, ASCE, 828-845. https://doi.org/10.1061/9780872620834.048

d'Angremond, K., van der Meer, J.W., de Jong, R.J., 1996. Wave Transmission at Low-Crested Structures. Proceedings of the 25th International Conference on Coastal Engineering, ASCE,
3305-3318. https://doi.org/10.1061/9780784402429.187

Hur, D.S., Cho, W.C., Yoon, J.S., Kim, I.H., Lee, W.D., 2014.

Control Technologies in Reduction Rip Currents around the Open Inlet between Two Submerged Breakwaters. Journal of Coastal Research, Special Issue 72, 75-80. https://doi.org/ 10.2112/SI72-014.1

Hur, D.S., Cho, W.C., Yoon, J.S., Kang, C., Lee, W.D., 2017 b. Applicability of Multiple Submerged Narrow-Crested Breakwaters for Reduction of Mean Water Level in Rear Side and Flow Control. Journal of Coastal Research, Special Issue, 79, 179-183. https://doi.org/10.2112/SI79-037.1

Hur, D.S., Lee, W.D., An, S.W., Park, J.B., 2010. A Numerical Study on Flow Control Structure of a New-Type Submerged Breakwater. Journal of Korean Society of Coastal and Ocean Engineers, 22(3), 181-190.

Hur, D.S., Lee, W.D., Cho, W.C., 2012a. Three-Dimensional Flow Characteristics around Permeable Submerged Breakwaters with Open Inlet. Ocean Engineering, 44, 100-116. https://doi. org/10.1016/j.oceaneng.2012.01.029

Hur, D.S., Lee, W.D., Cho, W.C., 2012b. Characteristics of Wave Run-up Height on a Sandy Beach behind Dual-Submerged Breakwaters. Ocean Engineering, 45, 38-55. https://doi.org/ 10.1016/j.oceaneng.2012.01.030

Hur, D.S., Lee, W.D., Cho, W.C., Jeong, Y.H., Jeong, Y.M., 2019a. Rip Current Reduction at the Open Inlet between Double Submerged Breakwaters by Installing a Drainage Channel. Ocean Engineering, 193, 106580. https://doi.org/10.1016/ j.oceaneng.2019.106580

Hur, D.S., Lee, W.D., Goo, N.H., Jeon, H.S., Jeong, Y.M., 2017 a. Development of New Type of Submerged Breakwater for Reducing Mean Water Level behind Structure. Journal of Ocean Engineering and Technology, 31(2), 130-140.

Hur, D.S., Jung, K.H., Park, J.R., Lee, W.D., 2019b. Wave Control Performance of Tide-Adapting Low-Crested Structure. Journal of Coastal Research, Special Issue 91, 116-120.

Hur, D.S., Jung, Y.M., Lee, W.D., 2019c. Hydrodynamic Characteristics of Tide-Adapting Low-Crested Structure. Journal of Ocean Engineering and Technology 33(1), 68-75.

Seabrook, S.R., Hall, K.R., 1998. Wave Transmission at Submerged Rubble Mound Breakwaters. Proceedings of the 26th International Conference on Coastal Engineering, ASCE, 2000-2013.

van der Meer, J.W., Briganti, R., Zanuttigh, B., Wang, B., 2005. Wave Transmission and Reflection at Low-Crested Structures: Design Formulae, Oblique Wave Attack and Spectral Change. Coastal Engineering, 52, 915-929. 